\title{
The effect of beliefs about breast cancer on stage and delay to presentation: results from a prospective study in urban South Africa
}

\author{
S Rayne, ${ }^{1}$ K Schnippel, ${ }^{2}$ S Grover, ${ }^{3}$ D Kruger,1 C Benn, ${ }^{1}$ C Firnhaber ${ }^{4}$ \\ 1 Department of Surgery, Helen Joseph Hospital, Faculty of Health Sciences, University of the Witwatersrand, Johannesburg, \\ South Africa. \\ 2 Health Economics Unit, School of Public Health and Family Medicine, Faculty of Health Sciences, University of Cape Town, \\ South Africa. \\ 3 Department of Radiation Oncology, University of Pennsylvania, Philadelphia, US, Princess Marina Hospital, Gaborone, \\ Botswana, Botswana-UPENN Partnership, Gaborone, Botswana. \\ 4 Clinical HIV Research Unit, Department of Internal Medicine, Faculty of Health Sciences, University of the Witwatersrand, \\ Johannesburg, South Africa.
}

Corresponding author: Sarah Rayne (rayne.sarah@gmail.com)

\begin{abstract}
Background: The disparity in breast cancer survival in Africa is often linked to poor education and awareness leading to late diagnosis and subsequent reduced survival. This study was designed to explore the relationship of attitudes and beliefs held regarding breast cancer to the stage and delay to diagnosis in South Africa. This study provies an epidemiological analysis of the spectrum of disease and outcomes of primary amputation for diabetic foot sepsis in a regional rural hospital. Methods: Women attending an open-access breast unit over 14 months with newly-diagnosed breast cancer answered a survey regarding their fears and beliefs of breast cancer care. Questions addressed demographic, socioeconomic and educational factors linked to delay, and documented time taken to care. Odds ratio with $95 \%$ confidence intervals were calculated to identify factors associated with advanced stage at presentation and delay greater than six months.

Results: Of the 233 participants the median (IQR) age was 56 years (46-65). The most common stage at presentation was Stage $3(55 \%)$, with $30.5 \%$ presenting with T4 tumour at presentation.

Most women believed cancer could be beaten (90.0\%), and their families would support them (92.8\%). They disagreed that cancer was a curse $(93.8 \%)$, punishment $(90.5 \%)$ or that alternative therapies or traditional healing would cure their cancer (75.3\% and $85.5 \%$ respectively). On univariate analysis, age under 45 years and transport difficulties predicted advanced stage at presentation. No socio-economic factors or beliefs increased the risk of delay to presentation.

Conclusion: Participants' beliefs about their new breast cancer were most commonly appropriate, and showed a low level of fatalism, in contrast to other studies in Africa. Whilst raising awareness may be important, efforts to increase awareness alone may not directly prevent the likelihood of late or advanced diagnosis in this population.
\end{abstract}

Keywords: Breast cancer; Barrier to care; Disparities; Surgery; Oncology

S Afr J Surg 2019;57(1)

http://dx.doi.org/10.17159/2078-5151/2018/v56n2a2704

\section{Background}

Breast cancer is the most common cancer to affect women in South Africa. Whilst the lifetime risk is lower than in highincome countries, ${ }^{1}$ outcomes are worse with reduced survival. This poor ratio of diagnosis to survival is often linked to difficulty in accessing care and poor availability of treatment options after diagnosis.-5 Screening and early diagnosis are limited and patients commonly present with advanced stage of disease limiting their outcomes despite treatment. Commonly cited or implied reasons for late diagnosis are often related in the literature to delay to care, both patient related delay, and provider (or system) delays. A delay of more than three months to presentation has been associated with more advanced breast cancer at diagnosis and decreased survival, ${ }^{6}$ however most studies from low- and middle-income countries (LMICs) indicate that the average delay exceeds this time. In countries of similar upper-middle income economic background to South Africa, delay to care (both patient- and provider-related) of more than three months ranges from $56 \%$ in Malaysia to $70 \%$ in Brazil. ${ }^{7,8}$

In South Africa, few studies have examined the management 
of breast cancer in the government health system beyond pathological studies. Little has been described regarding patient-related delays, or indeed the complex path women take both psychologically and physically to access care. Patientrelated delays commonly cited in other parts of Africa include socioeconomic and educational barriers, and indigent beliefs regarding cancer causes, symptoms and management. These beliefs may also include elements of 'cancer fatalism' where events are destined to happen with the individual relatively powerless to influence them. ${ }^{9}$ Previous studies in South Africa have found that most patients self-refer to tertiary care, often due to delays in the system ${ }^{10}$ and that farther geographical distance to hospital could be linked to late stage at presentation. ${ }^{11}$ An older study from 2010 aimed to assess breast knowledge in South Africa and indicated that poor knowledge was a main factor for delay, with less than $50 \%$ of respondents aware that changes in the breast may herald cancer. $^{12}$ The same study found that $44.9 \%$ of women felt they should not spend money on their health and $38.7 \%$ were not encouraged by families to seek healthcare. More than threequarters of patients reported that they would wait less than one week to tell someone once they suspected they might have cancer. ${ }^{12}$ The most recent qualitative study, amongst breast cancer patients, found low cancer awareness and frequent monitoring of symptoms until a change in symptom or disclosure to a family member precipitates healthcare review. ${ }^{13}$

In the absence of studies focusing on patients' own beliefs and the complex interplay between these views and their pathway to care, this study was designed to explore the relationship of attitudes and beliefs held regarding breast cancer and its management to the stage at presentation, and delay to diagnosis.

\section{Methods}

Women attending a South African government tertiary referral centre for breast cancer diagnosis and surgical management were approached to participate in a survey regarding their beliefs and fears surrounding breast cancer. The centre is an open access clinic for all patients with breast problems and routinely sees 4000 new patients each year and diagnoses 300-350 new breast cancers. The spectrum of breast problems and investigations in this urban centre in a limited resource setting has been previously described.${ }^{10}$ Consecutive women were included if they had a new diagnosis of a biopsy-proven breast cancer and accepted the invitation to participate during their post-diagnosis counselling by a clinician, with the survey administered within this period. Written consent was obtained, and the survey was administered by two trained research assistants, fluent in at least two languages. The survey was written in English and the assistants trained in the tool to minimise change in meaning during verbal translation. The questionnaire was completed in REDCap (hosted by the University of the Witwatersrand) and linked to the participant's clinical findings at presentation. Ethical approval was received from the Human Research Ethics Committee (Medical) of the University of the Witwatersrand (M111121).
The questionnaire comprised of multiple sections. The first established demographics, socio-economic situation, education, and self-described ability to access care. In the second section women were asked to quantify, from recollection, the length of time taken to attend the breast clinic, with the timeline separated into three categories: time taken to notice and acknowledge a breast symptom, time taken from then to access any healthcare services, and finally time taken from then to attend the open-access breast clinic. The final section comprised of 44 statements describing a fear or belief grounded in their breast cancer diagnosis or understanding of treatment and prognosis. These were expressed on a fourpoint Likert scale from strongly disagree to strongly agree. Many of these statements have been previously piloted and described ${ }^{15,16}$ and were augmented to include, around cancer, fatalism and health beliefs ${ }^{17,18}$ from similar studies. Internal consistency measurements for each subscale (fears, beliefs, fatalism and risk factors) found a Cronbach's alpha coefficient of $0.82,0.73,0.71$ and 0.81 respectively. Scales are considered acceptable with an alpha ranging from $0.70-0.95 .{ }^{19}$

\section{Data analysis}

Patients' characteristics were described, using frequencies and proportions, and categorised to facilitate analysis. Marital status categorised as partnered or unpartnered (which included women who were not in a relationship or widowed) and age was categorised as less than 45 years, 45-64 years or 65 years and older. Less than 45 years was defined as "young" breast cancer. Education was categorised according to the highest level of formal schooling obtained: grade 9 (approx. 14 years of age) and above grade 9 . Those who had achieved matriculation from secondary school and above were also differentiated from those who had no completion certification of secondary education.

Responses from the subscales for fears and beliefs were grouped according to those who expressed some fear or belief (agree or strongly agree) compared to those who did not. Time to presentation was comprised of time taken to acknowledge symptom (T-Ack), time to seek healthcare services (T-HS) and time taken to attend breast care clinic (T-BCC). Each was categorised as $<1 \mathrm{w}, 1$ week to 1 month, 1 month to 6 months, $>6$ months to 1 year and greater than 1 year. A total time to presentation (T-Tot) was calculated as the sum of the three individual time periods, and grouped as either 6 months or less, and greater than 6 months.

Clinical stage at presentation was determined from the clinical "TNM" staging system (AJCC, 8th edition) ${ }^{20}$ of the examining physician. This was then categorised as early (between stage 1 and stage 2a) and late staged (stage $2 \mathrm{~b}$ to stage 4). Stage 4 disease was included but may have been relatively underrepresented as these patients often may access medical oncological care without first attending a breast surgical clinic. For determination of delay by stage, patients with Stage 0 were excluded because of the relationship with screening, rather than clinically detected disease in this group. Two-sided differences of proportions were compared using Pearson $\mathrm{chi}^{2}$ test. A p-value $<0.05$ was considered statistically 
Table 1 Demographic and clinical characteristics of patients presenting for care $(n=252)$

\begin{tabular}{|c|c|c|}
\hline \multirow[t]{2}{*}{ Description } & \multicolumn{2}{|c|}{ Total $(n=233)$} \\
\hline & $\mathrm{n}$ & $\%$ \\
\hline \multicolumn{3}{|l|}{ Age $(n=230)$} \\
\hline$<45$ years & 48 & 20.9 \\
\hline $45-64$ years & 121 & 73.5 \\
\hline$>65$ years & 61 & 26.5 \\
\hline Median years (IQR) & 56 & $(46-65)$ \\
\hline \multicolumn{3}{|l|}{ Relationship status $(\mathrm{n}=\mathbf{2 2 3})$} \\
\hline Partnered & 112 & 50.2 \\
\hline Not partnered & 111 & 49.8 \\
\hline \multicolumn{3}{|l|}{ Family History $(n=225)$} \\
\hline Breast cancer in close relative & 20 & 8.9 \\
\hline \multicolumn{3}{|c|}{ Formal education achieved beyond Grade $9(n=219)$} \\
\hline No education beyond Grade 9 & 69 & 31.5 \\
\hline \multicolumn{3}{|l|}{ Matriculated from school $(n=219)$} \\
\hline Yes & 76 & 34.7 \\
\hline \multicolumn{3}{|l|}{ Dependants $(n=200)$} \\
\hline No dependants & 51 & 25.5 \\
\hline 1-3 dependants & 65 & 32.5 \\
\hline More than 3 & 84 & 42.0 \\
\hline \multicolumn{3}{|l|}{ Have cell phone $(n=219)$} \\
\hline Yes - contract & 34 & 15.5 \\
\hline Yes - top up & 172 & 78.5 \\
\hline \multicolumn{3}{|c|}{ Do you access the internet? $(n=220)$} \\
\hline No & 139 & 63.2 \\
\hline Yes - occasionally & 46 & 20.9 \\
\hline Yes - every day & 35 & 15.9 \\
\hline \multicolumn{3}{|l|}{ Confident reader $(\mathrm{n}=\mathbf{2 2 1})$} \\
\hline Yes & 211 & 95.5 \\
\hline \multicolumn{3}{|l|}{ Employed, job $(\mathrm{n}=\mathbf{2 2 2})$} \\
\hline Yes & 70 & 31.5 \\
\hline \multicolumn{3}{|l|}{ Religion beliefs $(n=223)$} \\
\hline Yes - Christian & 193 & 86.6 \\
\hline Yes - Muslim & 13 & 5.8 \\
\hline Yes - Traditional African & 4 & 1.8 \\
\hline Yes - other & 13 & 5.8 \\
\hline \multicolumn{3}{|c|}{ Attend religious meetings at least once a week $(n=196)$} \\
\hline Yes & 123 & 62.8 \\
\hline \multicolumn{3}{|c|}{ Breast cancer in close relative or friend $(n=100)$} \\
\hline Alive and cancer-free & 22 & 22.0 \\
\hline Alive (with cancer) & 12 & 12.0 \\
\hline Died from cancer & 60 & 60.0 \\
\hline \multicolumn{3}{|l|}{ Stage at presentation $(n=231)$} \\
\hline 1 & 33 & 14.3 \\
\hline $2 \mathrm{a}$ & 36 & 15.6 \\
\hline $2 b$ & 27 & 11.7 \\
\hline
\end{tabular}

$\begin{array}{lcc}3 \mathrm{a} & 56 & 24.2 \\ 3 \mathrm{~b} & 68 & 29.4 \\ 3 \mathrm{c} & 5 & 2.2 \\ 4 & 6 & 2.6 \\ \text { Tumour T4 on presentation }(\mathbf{n}=\mathbf{2 2 6}) & & \\ \quad \text { Yes } & 73 & 32.3 \\ \text { Total delay to presentation } & & \\ \quad<1 \text { month } & 38 & 21.0 \\ \text { 1 month }-6 \text { months } & 78 & 43.1 \\ >6 \text { months }-1 \text { year } & 38 & 21.0 \\ >1 \text { year } & 27 & 14.9\end{array}$

significant. Poisson's regression methods of calculating odds ratio with $95 \%$ confidence intervals to compare early stage (up to Stage 2a) with advanced breast cancer (Stage2b and beyond) were used to identify factors associated with presentation with advanced stage.

\section{Results}

During the study period of 14 months, 233 participants completed the survey (response rate of $65.5 \%$ of all newly diagnosed breast cancers).

\section{Demographic and clinical characteristics:}

The median (IQR) age was 56 years (46-65), with 23.6\% under 45 years old. Most patients had a partner, had some dependants and had received a formal education beyond grade 9 . The most common stage at presentation was Stage $3(50.4 \%$ ), with $30.5 \%$ of all cancers presenting as T4 (skin involvement (T4b) 23.5\%, inflammatory (T4d) 6.2\%). Only 5\% presented with metastatic disease at presentation after investigations. These, and further characteristics are summarised in Table 1.

\section{Fears and beliefs:}

Figure 1 shows the statements with the percentages of respondents' answers. In general, the responses showed a positive outlook with high agreement to statements such as 'my family will support me (92.8\% agree/strongly agree) and I believe I can beat cancer $(90.0 \%$ agree/strongly agree). Equally emphatic was disagreement to both ideas of malevolent external origin (someone has cursed me with this cancer, $93.7 \%$ disagree/strongly disagree; this cancer is a punishment $90.2 \%$ disagree/strongly disagree) and resistance to biomedical therapies (cure with traditional healing $85.5 \%$ disagree/strongly disagree; cure with alternative therapy $75.3 \%$ disagree/strongly disagree; people die when they go to hospital $97.0 \%$ disagree/strongly disagree). Most questions regarding fatalistic beliefs were disagreed with, and only “... it is part of god's plan" and "... it was meant to be" were agreed with by more than one quarter of participants $(46.4 \%$ and $54.5 \%$ respectively).

Overall, there were few beliefs that were strong predictors for presentation with late stage or delay to presentation. On 


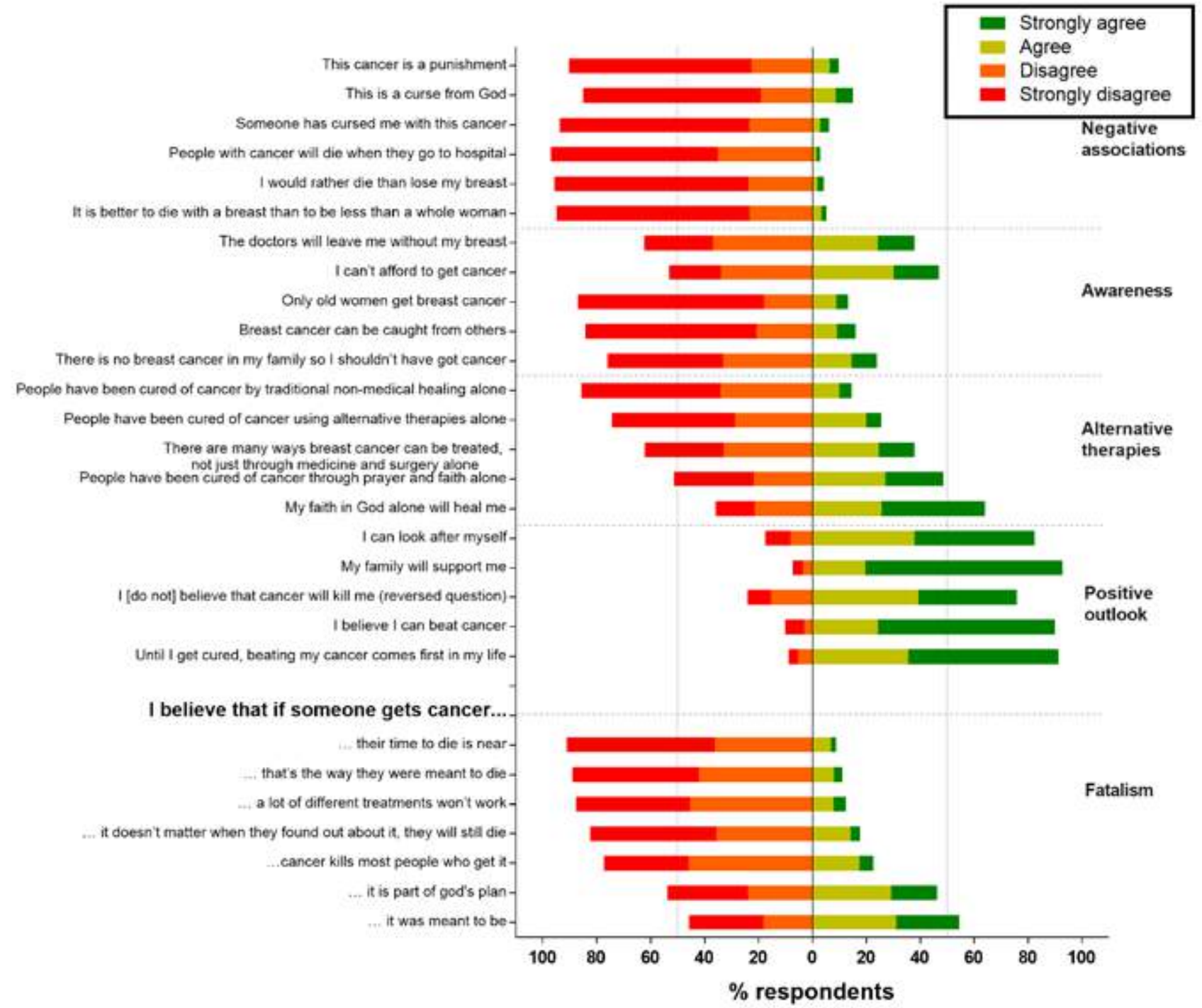

Figure 1. Participants beliefs, by percentage of responses.

univariate analysis, young women were $20 \%$ more likely to present with an advanced breast cancer (IRR 1.20 95\%CI 1.01-1.42). Whilst limited education was not related to advanced disease, being a confident reader was protective against late presentation (IRR 0.77 95\% CI $0.61-0.96$ ). Patients who presented with an advanced cancer were more likely to believe that cancer could be caught from others (IRR1.28 95\% CI $1.06-1.54$ ), that they "could not afford to get cancer" (IRR1.24 95\% CI 1.03-1.50), and to state that they "would rather die than lose a breast" (IRR 1.29 95\% CI 1.01-1.66) or that if "someone gets cancer that was the way they were meant to die" (IRR 1.29 95\% CI 1.06-1.58). Women with locally-advanced cancer were also $20 \%$ more likely to believe that cancer can be cured by methods other than medicine and surgery (IRR1.19 95\% CI 1.00-1.42), however no other belief statements in alternative therapies showed significance here.

Self-reported transport difficulties also predicted late presentation in the univariate model (IRR1.26 95\% CI 1.07-1.49), and when the model was adjusted for each of the beliefs with a significant relationship, the likelihood of late presentation was strengthened in women with transport difficulties if they believed that they "would rather die than lose a breast" (aIRR1.28 95\% CI 1.09-1.52), believed cancer could be caught from another person (aIRR1.27 95\% CI 1.06-1.52), believed that cancer can be cured by methods other than medicine and surgery, or traditional non-medical methods alone (aIRR1.38 95\% CI 1.17-1.63 and aIRR1.32 95\% CI 1.11-1.57 respectively) and believed that cancer "will eventually kill me" (aIRR1.34 95\% CI 1.12-1.59) or if "someone gets cancer that was the way they were meant to die" (aIRR1.34 95\% CI 1.14-1.58).

In considering delay to presentation, no socio-economic factors or beliefs increased the risk of delay more than six months including travel more than one hour, transport difficulties, lack of employment, or age. Only agreement with the statement "My family will support me" was associated with a total time to presentation within six months (IRR 1.26 95\% CI 1.02-1.59). 
Agreement with the statement 'I am afraid of cancer' was not statistically significantly associated with delayed presentation or locally advanced.

Good social support and interaction with the world (via cell phone usage and internet) were not associated with an earlier stage at presentation or decreased delay. In considering religion, women who attended a religious meeting more than once a week were no more likely to present with late disease, although regular attendance predicted beliefs that God alone could heal disease (RR1.43 95\% CI 1.07-1.91). Regular attendance at church was found in older women, with less education, and less access to the internet $(\mathrm{p}<0.001, \mathrm{p}=0.05$, $\mathrm{p}=0.02)$.

\section{Discussion}

South Africa is an upper-middle-income country with a relatively secure infrastructure, and Johannesburg is a relatively affluent city with relatively good access to local hospitals and specialised breast care. Within this setting, however, more than three quarters of patients presented to an open-access breast clinic with advanced breast cancer and more than half of these with a T4 tumour. This study was designed to determine the relationship between beliefs and fears and an advanced presentation or delay to presentation in breast cancer.

Our study found that the predictors of late stage disease were socio-economic as well as related to attitudes of disease. We found that transport difficulties most consistently predicted an increased stage at presentation (and confidence in reading was protective of this), whilst there were no identified factors which increased the likelihood of patient-related delay to care. A recent study using the pilot questionnaire in this same population $^{16}$ found that demographic and socio-economic factors (which often overlap in South Africa due to the legacy of Apartheid-era inequity) predicted for some beliefs, particularly regarding alternative treatment regimens and negative statements about death and disfigurement. However, this more comprehensive study has found that most of these beliefs were unrelated to stage of disease at presentation, as well as unrelated to delay to care. Therefore, although socio-economics may predict beliefs, beliefs alone did not consistently predict stage of disease. Furthermore, while fears and beliefs may impact on time to present to a breast specialist clinic, the linear relationship that is conceived of in literature between fear and misconception leading to a reticence to present and therefore delay to care with an advanced stage of cancer could not be traced here.

The implication of these findings is that the continual message of breast education and awareness, whilst an important strategy for advocacy may be failing to fully enable women to reach the care appropriate for them. This study found that late presentation was more consistently related to issues of navigation to the hospital through transport problems, money worries and through literacy. There was a relatively high level of appropriate agreement and disagreement to the belief questions, indicating that in this group of women of whom over one-third had T4 tumours, their breast "awareness" and education were satisfactory. Therefore, in addition to advocating breast education, a more holistic recognition that empowering women through raising the effective education levels of all women in the community could raise not only their awareness of disease, but improve their ability to access care. Until this is achieved, women are still likely to present with late stage disease. This assertion is supported by the finding that confidence in reading rather than years of education was more predictive of earlier presentation.

Identifying that transport difficulties were related to both late presentation and delay to presentation (risks of which were independent of each other) would also indicate that further work also needs to be done in improving women's navigation to appropriate care from the community, through easing their transport and work difficulties. This study will provide useful information for government and local advocacy groups as to the best use of resources in reducing the breast cancer burden by decreasing late presentation.

Overall this study found that women presenting for breast cancer diagnosis had a relatively appropriate understanding of breast cancer. Few patients had negative beliefs about the origin of their cancer, or surgical treatment. The area of heterogeneity that was most noted was around beliefs in alternative methods of cure, whilst only less than one quarter of patients believed in alternative or traditional methods of cure $(24.5 \%$ and $14.2 \%$ agreed/strongly agreed respectively), nearly half stated they believed prayer and faith or God alone could cure them (48.2\% and $64.1 \%$ agreed/strongly agreed). None of these beliefs predicted delay to presentation or stage at presentation, and represent an interesting duality of belief between what is stated, and what is carried out by the patient. The degree of cancer fatalism in this population also differed from those in other African studies. Akhigbe et al. ${ }^{18}$ found high levels of fatalism amongst a Nigerian health professional population with agreement to each question ranging from $45-82 \%$, and from a series reported in Ghanaian women, ${ }^{21}$ they too had higher levels of fatalism compared to our South African group. These beliefs are in sharp contrast to those described 15 years ago in South Africa where nursing staff reported "with breast cancer who wanted a mastectomy would die because their husbands refused to let them be "disfigured" 22 or the "...patient sought help first from a traditional healer as a way of dealing with the cause of the disease..." ${ }^{23}$ but supported by more recent studies in a similar group of South African women. ${ }^{12}$ This study did not find a simple association between attitudes and beliefs around breast cancer and either stage at presentation or delay to presentation. The participants were a heterogeneous group, reporting prompt presentation or delayed presentation equally with early or late stage disease. On reviewing the literature regarding similar studies from other low- and middle- income countries, we did not find the standard associations of low education, poor employment and lack of awareness that other studies have found, even those carried out in urban settings in tertiary referral centres such as in Nigeria, ${ }^{24}$ Ghana, ${ }^{25,26}$ and Rwanda. ${ }^{27}$ In these circumstances, using the health belief model to understand why and when 
patients access breast care may not necessarily be applicable, as persuading a woman of the significance of her problem does not necessarily equip her with the tools to seek care. It may be that recognising the disparity in socio-economic capital and addressing this inequity through increasing women's education levels, literacy and empowerment on a governmental level, together with facilitating physical access to care, will reduce late stage disease more than high-profile media campaigns.

There are limitations to this study. The small sample size and single study site limit the suitability of the findings to similar breast centres. However, as the management of breast cancer becomes more specialised, more tertiary centres are being identified in Africa, ${ }^{28}$ and these findings may help guide further work in understanding and assisting the women accessing care. The reflective retrospective nature of some of the questions, designed to give voice to patients concerns, may illicit bias responses despite separating the clinicians from those administering the survey. Allowing the participants voices to be better heard through qualitative studies would also enable better understanding of the nuances of beliefs around cancer. Whilst some work has been done in South Africa, ${ }^{13,29}$ more is required. In addition, the beliefs reported here are only of those who attended for care. There is a cohort of women with breast cancer who never reach a referral centre, either due to complete inability to access the system through socio-economic or other constraints, or present so late in the disease process that referral for tertiary care is inappropriate. Only $5 \%$ of the women in this study had Stage 4 disease, which may not reflect the true burden of metastatic disease in our environment.

\section{Conclusion}

This study examined the beliefs of women with a new breast cancer diagnosis and found that most held positive and appropriate beliefs regarding breast cancer and treatment options. There were low levels of fatalism in the group, which contrasts with other studies from Africa and with older studies in South Africa. The relationship of stage of disease and delay to presentation was more associated with structural barriers such as transport difficulties, than with the investigated beliefs, or demographic characteristics. Although education and awareness are the most common strategies for advocacy in South Africa, developing different models to improve access to care, such as facilitating transport, may be beneficial to the population served.

\section{Financial support:}

This study had no funding support.

\section{Conflict of interest:}

The authors declare no conflicts of interest.

\section{REFERENCES}

1. South Africa National Cancer Registry, National Institute for Occupational Health. Cancer in South Africa 2012 Full Report [Internet]; 2012. Available from: http://www.nioh. ac.za/?page=national_cancer_registry\&id $=41$

2. Unger-saldaña K. Challenges to the early diagnosis and treatment of breast cancer in developing countries. World J Clin Oncol. 2014;5(3):465-78.

3. Ginsburg O, Badwe R, Boyle P, Derricks G, Dare A, Evans $\mathrm{T}$, et al. Changing global policy to deliver safe, equitable, and affordable care for women's cancers. Lancet [Internet]. 2016;389(10071):871-80. Available from: http://linkinghub. elsevier.com/retrieve/pii/S0140673616313939

4. Sharma K, Costas A, Damuse R, Hamiltong-Pierre J, Pyda J, Ong CT, et al. The Haiti Breast Cancer Initiative: Initial Findings and Analysis of Barriers-to-Care Delaying Patient Presentation. J Oncol [Internet]. Jan 2013 [accessed on 5 Aug 2015];2013:206367. Available from: http:/www.pubmedcentral.nih.gov/articlerender. fcgi? artid $=3687503 \&$ tool $=$ pmcentrez\&rendertype $=$ abstract

5. Jedy-Agba E, McCormack V, Adebamowo C, dos-Santos-Silva I. Stage at diagnosis of breast cancer in sub-Saharan Africa: a systematic review and meta-analysis. Lancet Glob Heal [Internet]. 2016;4(12):e923-35. Available from: http://dx.doi. org/10.1016/S2214-109X(16)30259-5

6. Ramirez AJ, Westcombe AM, Burgess CC, Sutton S, Littlejohns P, Richards MA. Factors predicting delayed presentation of symptomatic breast cancer: A systematic review. Lancet [Internet]. Apr 1999 [accessed on 24 Jul 2015 ];353(9159):112731. Available from: http://www.sciencedirect.com/science/ article/pii/S014067369902142X

7. Lim JNW, Potrata B, Ng C, Aw T-C, Dahlui M, Taib N, et al. Barriers to early presentation of self-discovered breast cancer in Singapore and Malaysia: a qualitative multicentre study. BMJ Open. 2015;5(12):e009863.

8. Barros AF, Uemura G, Soares JL. Time to access breast cancer treatment in the Federal District, Central Brazil. Brazilian J Gynecol Obstet. 2013;35(10):1-9.

9. Talbert PY. The Relationship of Fear and Fatalism with Breast Cancer Screening Among a Selected Target Population of African American Middle Class Women. J Soc Behav Heal Sci. 2008;2(1):96-110.

10. Rayne S, Lince-deroche N, Hendrickson C, Shearer K, Moyo F, Michelow $\mathrm{P}$, et al. Characterizing breast conditions at an openaccess breast clinic in South Africa: a model that is more than cancer care for a resource-limited setting. BMC Health Serv Res [Internet]. 2017;17(63):1-10. Available from: http://dx.doi. org/10.1186/s12913-016-1959-4

11. Dickens C, Joffe M, Jacobson J, Venter F, Schüz J, Cubasch $\mathrm{H}$, et al. Stage at breast cancer diagnosis and distance from diagnostic hospital in a periurban setting: A South African public hospital case series of over 1,000 women. Int J Cancer. 2014;135:2173-82.

12. Maree JE, Wright SCD. How would early detection be possible? An enquiry into cancer related knowledge, understanding and health seeking behaviour of urban Black women in Tshwane, South Africa. Eur J Oncol Nurs [Internet]. 2010;14(3):190-6. Available from: http://www.ncbi.nlm.nih. gov/pubmed/19944646

13. Moodley J, Cairncross L, Naiker T, Momberg M. Understanding pathways to breast cancer diagnosis among women in the Western Cape Province, South Africa: a qualitative study. BMJ Open [Internet]. 2016;6(1):e009905. Available from: http:// 
bmjopen.bmj.com/lookup/doi/10.1136/bmjopen-2015-009905

14. Harris PA, Taylor R, Thielke R, Payne J, Gonzalez N, Conde JG. Research electronic data capture (REDCap) - A metadatadriven methodology and workflow process for providing translational research informatics support. J Biomed Inform [Internet]. 2009;42(2):377-81. Available from: http://dx.doi org/10.1016/j.jbi.2008.08.010

15. Rayne S, Schnippel K, Wright K, Kruger D, Firnhaber C, Benn C. Fear of Treatments Surpasses Demographic and Socioeconomic Factors in Affecting Patients With Breast Cancer in Urban South Africa. J Glob Oncol. 2016;3(2):125-34.

16. Rayne S, Schnippel K, Benn C, Kruger D, Wright K, Firnhaber C. The effect of Access to Information on Beliefs Surrounding Breast Cancer in South Africa. J Cancer Educ. 2017.

17. Powe BD. Cancer fatalism among elderly Caucasians and African Americans. Oncol Nurs Forum. Oct 1995;22(9):1355-9.

18. Akhigbe A, Akhigbe K. Effects of Health Belief and Cancer Fatalism on the Practice of Breast Cancer Screening Among Nigerian Women. In: Mammography- Recent Advances. 2012. p. 71-88.

19. Tavakol M, Dennick R. Making sense of Cronbach 's alpha. Int J Med Educ. 2011;2:53-5.

20. Giuliano AE, Connolly JL, Edge SB, Mittendorf EA. Breast Cancer - Major Changes in the American Joint Committee on Cancer Eighth Edition Cancer Staging Manual. CA Cancer J Clin. 2017;67(4).

21. Mayo RM, Hunter A, Parker VG. Fatalism toward breast cancer among the women of Ghana. Health Care Women Int 2003;24(7):608-16.
22. Cooper S, Mullin V. Quality of Life of Cancer patients in underserved populations in South Africa. J Psychosoc Oncol. 2001;19(2):1-16

23. Vorobiof D, Sitas F, Vorobiof G. Breast cancer incidence in South Africa. J Clin Oncol. 2001;19(18 Suppl):125S-127S.

24. Ibrahim N, Oludara M. Socio-demographic factors and reasons associated with delay in breast cancer presentation: A study in Nigerian women. Breast [Internet]. 2012;21(3):416-8. Available from: http://dx.doi.org/10.1016/j.breast.2012.02.006

25. Opoku SY, Benwell M, Yarney J. Knowledge, attitudes, beliefs, behaviour and breast cancer screening practices in Ghana, West Africa. Pan Afr Med J. Jan 2012;11:28.

26. Clegg-Lamptey JNA, Dakubo JCB, Attobra YN. Psychosocial aspects of breast cancer treatment in Accra, Ghana. East Afr Med J. Jul 2009;86(7):348-53.

27. Pace L, Mpunga $T$, Hategekimana V, Jean-Marie Vianney Dusengimana, Habineza H, Bigirimana JB, et al. Delays in Breast Cancer Presentation and Diagnosis at Two Rural Cancer Referral Centers in Rwanda. Oncologist. 2015;20:780-8.

28. Vanderpuye VDNK, Olopade OI, Huo D. Pilot Survey of Breast Cancer Management in Sub-Saharan Africa. J Glob Oncol. 2107;3(3):194-5

29. Van der Wiel R. Unravelling stereotype, unanticipated sociality: Breast cancer treatment at a public healthcare facility in post-apartheid Johannesburg. [Internet]. University of the Witwatersrand, South Africa. University of the Witwatersrand, Johannesburg; 2013. Available from: http://hdl.handle. net/10539/13184 